Journal of

Molecular Microbiology

and Biotechnology

\title{
Gas Vesicles across Kingdoms: A Comparative Solid-State Nuclear Magnetic Resonance Study
}

\author{
Eugenio Daviso ${ }^{\text {a, b }}$ Marina Belenky ${ }^{a}$ Robert G. Griffin ${ }^{b}$ Judith Herzfeld ${ }^{a}$ \\ ${ }^{a}$ Department of Chemistry, Brandeis University, Waltham, Mass., and ${ }^{b}$ Francis Bitter Magnet Laboratory and \\ Department of Chemistry, Massachusetts Institute of Technology, Cambridge, Mass., USA
}

\section{Key Words}

Cyanobacteria $\cdot$ Anabaena $\cdot$ Haloarchaea $\cdot$ Halobacterium . Gas vesicle protein A. Amyloid - Supramolecular assembly . Protein structure $\cdot$ Chemical shift assignment

\begin{abstract}
The buoyancy organelles of aquatic microorganisms have to meet stringent specifications: allowing gases to equilibrate freely across the proteinaceous shell, preventing the condensation of water vapor inside the hollow cavity and resisting collapse under hydrostatic pressures that vary with column depth. These properties are provided by the 7- to 8-kDa gas vesicle protein A (GvpA), repeats of which form all but small, specialized portions of the shell. Magic angle spinning nuclear magnetic resonance is uniquely capable of providing high-resolution information on the fold and assembly of GvpA. Here we compare results for the gas vesicles of the haloarchaea Halobacterium salinarum with those obtained previously for the cyanobacterium Anabaena flos-aquae. The data suggest that the two organisms follow similar strategies for avoiding water condensation. On the other hand, in its relatively shallow habitat, $H$. salinarum is able to avoid collapse with a less costly GvpA fold than is adopted by A. flosaquae.

Copyright $\odot 2013$ S. Karger AG, Basel
\end{abstract}

\section{Introduction}

A wide range of microorganisms deploy gas vesicles to regulate their buoyancy. These include over 150 species in at least five phyla of Bacteria and two phyla of Archaea [Walsby, 1994]. The hollow organelles are most commonly found in aquatic microorganisms. However, gas vesicles have been observed in a soil organism [Omelchenko et al., 1993] and in an enterobacterium [Ramsay et al., 2011], where their purpose is less obvious.

The most thoroughly studied gas vesicles are those of the cyanobacterium Anabaena flos-aquae and the haloarchaea Halobacterium salinarum and Haloferax mediterranei, and the properties shared across these two domains are quite remarkable. Although the entirely proteinaceous shells are only $20 \AA$ thick on average [Blaurock and Walsby, 1976; Blaurock and Wober, 1976], they resist collapse. And while the gaseous contents equilibrate with the surroundings [Walsby, 1969, 1982; Walsby et al., 1992; Walsby and Simpson, 1984], water does not condense inside.

The vesicle shells remain intact on washing with urea or detergent and these stripped bodies are constructed almost exclusively of the 7- to 8 - $\mathrm{kDa}$ gas vesicle protein $\mathrm{A}$ (GvpA) [Walsby and Hayes, 1988] which is not cross-

\section{KARGER}

E-Mail karger@karger.com

www.karger.com $/ \mathrm{mmb}$ (c) 2013 S. Karger AG, Basel

1464-1801/13/0235-0281\$38.00/0
Judith Herzfeld

Department of Chemistry, Brandeis University

415 South Street

Waltham, MA 02454-9110 (USA)

E-Mail herzfeld@brandeis.edu 
linked or otherwise posttranslationally modified [Belenky et al., 2004]. The arrangement of GvpA in a low-pitch helix [Offner et al., 1998] lends the vesicles a ribbed appearance with a $46-\AA$ spacing between the ribs [Blaurock and Walsby, 1976; Blaurock and Wober, 1976] (fig. 1). Observations of prominent X-ray reflections with $4.7-\AA$ Bragg spacings [Blaurock and Walsby, 1976; Blaurock and Wober, 1976] suggest extended $\beta$-sheet structures that could account for the amyloid-like insolubility of the vesicles [Bayro et al., 2012].

Given these shared properties, it is not surprising that the GvpA sequences are highly homologous (as illustrated in fig. 2) [Sivertsen et al., 2009; Walker et al., 1984]. Furthermore, given the unusual properties of gas vesicles, it is not surprising that GvpA's share little homology with other proteins [Ezzeldin et al., 2012; Strunk et al., 2011].

However, gas vesicles from different species also differ in some significant ways. For example, while GvpA carries a net negative charge in both $A$. flos-aquae and $H$. salinarum, this charge is much greater in the species adapted to high ionic strength environments than in the fresh water organism (fig. 2). More vividly, species that inhabit deep waters, like A. flos-aquae, build narrower shells, with considerably higher collapse pressures, than species that inhabit shallow waters, like H. salinarum (fig. 1). It is thought that the surface-to-volume ratio is the main determinant of the strength of the stripped shells. However, it has been proposed that the orientation of the $\beta$-sheets also plays a role. X-ray studies of aligned A. flosaquae vesicles showed that the $\beta$-strands are oriented at $36^{\circ}$ relative to the vesicle axis [Blaurock and Walsby, 1976]. Where they are sufficiently exposed along the ribs, this orientation of the $\beta$-strands has been confirmed by atomic force microscopy [McMaster et al., 1996]. It follows that the hydrogen bonds in the $\beta$-sheets must be inclined $54^{\circ}$ from the vesicle axis, a 'magic angle' that is thought to lend extra strength to the assembly [Walsby, 1994]. The corresponding information is not available for $H$. salinarum vesicles because they do not have a sufficiently large aspect ratio to be aligned easily.

Low-resolution structural information, such as that described above, was all that was available for gas vesicles until recently. The large difference in electron density between the gaseous interior of the vesicles and the aqueous exterior results in multiple scattering that frustrates highresolution electron microscopy. Also, the insolubility of the vesicles in all but highly protic, irreversibly denaturing solvents precludes the application of solution nuclear magnetic resonance (NMR) or crystallography. However,
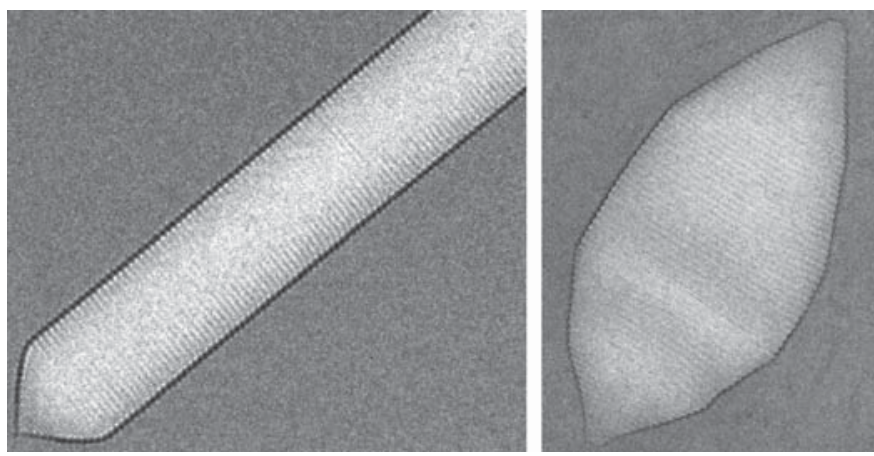

Fig. 1. Electron micrographs of gas vesicles from A. flos-aquae (left, obtained in collaboration with C. Xu, Brandeis University) and $H$. salinarum (right, obtained in collaboration with L.A. Melanson and D. DeRosier, Brandeis University) scaled to approximately match the $46-\AA$ spacings of their ribs. On closer examination of the images, a bipolar structure is evident from the opposite orientations of the rib protrusions on either side of an apparent seam.

significant inroads have recently been made with magic angle spinning (MAS) solid-state NMR applied to intact (though collapsed) vesicles of $A$. flos-aquae. The significant findings are:

(1) general agreement with the central $\alpha-\beta-\beta-\alpha$ secondary structure predicted from the primary sequence (fig. 3) [Sivertsen et al., 2010],

(2) polymorphism of the GvpA, such that the building block of the vesicles is an asymmetric dimer in which the odd-membered $\beta$-turn is shifted by one residue between the two monomers [Bayro et al., 2012; Sivertsen et al., 2009], and

(3) the ribs of the vesicle are formed by a continuous cross- $\beta$ ribbon that winds around the axis of the vesicle [Bayro et al., 2012].

The polymorphism is critical because it explains how the strands in the $\beta$-sheet can be oriented at $36^{\circ}$ to the vesicle axis without situating polar residues at the interior (putatively highly hydrophobic) surface of the shell or incurring significant electrostatic penalties in the arrangement of oppositely charged residues [Sivertsen et al., 2009]. The question that we now ask, with further MAS NMR studies, is whether these detailed properties of A. flos-aquae vesicles are shared by the gas vesicles of $H$. salinarum. On the one hand, we might expect that they would be, given the similar secondary structure predictions (see fig. 3). On the other hand, the $H$. salinarum vesicles are not built to withstand the pressures that are experienced by $A$. flos-aquae. 
AVEKTNSSSSLAEVIDRILDKGIVIDAWVRVSLVGIELLAIEARIVIASVETYLKYAEAVGLTQSAAVPA AQPDSSGLAEVLDRVLDKGVVVDVWARVSLVGIEILTVEARVVAASVDTFLHYAEEIAKIEQAELTAGAEAAPEA AQPDSSSLAEVLDRVLDKGVVVDVWARISLVGIEILTVEARVVAASVDTFLHYAEEIAKIEQAELTAGAEAPEPAPEA VQPDSSSLAEVLDRVLDKGVVVDVWARISLVGIEILTVEARVVAASVDTFLHYAEEIAKIEQAELTAGAEAAPTPEA

Fig. 2. Primary sequences of GvpA in the cyanobacterium A. flos-aquae (top) and in the haloarchaea H. salinarum (middle pair), and $H$. mediterranei (bottom). Substitutions in the unshaded, central region are few and highly conservative. Nonconservative variations in the shaded, peripheral regions add considerable negative charge to the halophile proteins.

AVEKTNS SSSLAEVIDRILDKGIVIDAWVRVSLVGIELLAIEARIVIASVETYLKYAE AVGLTQSAAVPA

9645689887899999875014088444899871123443362031040786999999858753113999

CCCCCCC CCCHHHHHHHHHHCCEEEEEEEEEEECCEEEEEEEEEEEHHHHHHHHHHHH HHCCCCCCCCCC

CCCC CCCHHHHHHHHHCCEEEEEEEEEEECCEEEEEEEEEEEEEEHHHHHHHHH HHHHHHHHHHHHCCCCCCCC 999978689999987513528855478886003456468657623378799999997101134674163469999 AQPD SSGLAEVLDRVLDKGVVVDVWARVSLVGIEILTVEARVVAASVDTFLHYAE EIAKIEQAELTAGAEAAPEA

Fig. 3. Secondary structure predictions from PSIPRED v3.0 for the GvpA of A. flos-aquae (top) and in the dominant GvpA of H. salinarum (bottom). Shading as in figure 2. $\mathrm{C}=\mathrm{Coil}, \mathrm{H}=$ helix, $\mathrm{E}=$ strand, with confidence ranging from 0 (low) to 9 (high). In both cases, all the glycine residues are found near transitions between secondary conformations.

\section{Results}

\section{Dynamics}

Figure 4 shows that the dynamics of GvpA in H. salinarum are similar to those observed in A. flos-aquae [Sivertsen et al., 2010]. The relatively small cross-polarization enhancement (fig. 4a) over direct polarization (fig. $4 \mathrm{~b}$ ) indicates considerable mobility in the protein. However, only saturated groups $(0-80 \mathrm{ppm})$ are sufficiently mobile to be detected in an INEPT (Insensitive Nuclei Enhanced by Polarization Transfer) experiment (fig. 4c).

\section{Polymorphism}

The first indication of dimorphism in the GvpA of $A$. flos-aquae was excess resonances in distinctive regions of the NMR spectrum. GvpA of A. flos-aquae has 3 glycine residues and 11 alanine residues. However, more than 3 glycine resonances and more than 11 alanine resonances appear in 2D correlation spectra [Sivertsen et al., 2009]. In contrast, although GvpA of $H$. salinarum has more glycine and alanine residues ( 4 and 14, respectively), the glycine and alanine regions of the ${ }^{13} \mathrm{C}-{ }^{13} \mathrm{C}$ correlation spectra are simpler, with no evidence of extra, distinct signals (fig. 5, 6). Thus, in contrast to the case in A. flos-aquae, there is no evidence for dimorphism in H. salinarum. Although there remain other reasons to think that the building block of the gas vesicle is a dimer in the case of $H$. salinarum (see Discussion), there is no reason to think that the dimer is asymmetric.

\section{Chemical Shift Assignments}

Sequential assignments were based primarily on a ${ }^{15} \mathrm{~N}-{ }^{13} \mathrm{C}-{ }^{13} \mathrm{C}$ spectrum [Daviso et al., 2013], representative slices of which are shown in figure 7 and 8 . The third dimension helps to separate and resolve peaks that overlap in the $2 \mathrm{D}$ spectra.

The use of ZF-TEDOR in the first mixing step simultaneously couples a backbone ${ }^{15} \mathrm{~N}$ with the ${ }^{13} \mathrm{CA}$ of the same residue and the ${ }^{13} \mathrm{CO}$ of the previous residue. This is illustrated in figure 7 , in which the slice of the spectrum corresponding to the ${ }^{15} \mathrm{~N}$ chemical shift of the V47 amide shows correlation with V47CA and S46CO. It is also illustrated in figure 8 by the appearance of the CA$\mathrm{CO}$ and CO-CA correlations of residue $i$ at self-consistent chemical shifts in the slices of the spectrum corresponding to the ${ }^{15} \mathrm{~N}$ amide signals of residues $i$ and $i+$ 1 , respectively.

Assignments are further facilitated by a long DARR mixing period for the ${ }^{13} \mathrm{C}-{ }^{13} \mathrm{C}$ recoupling, which transfers 


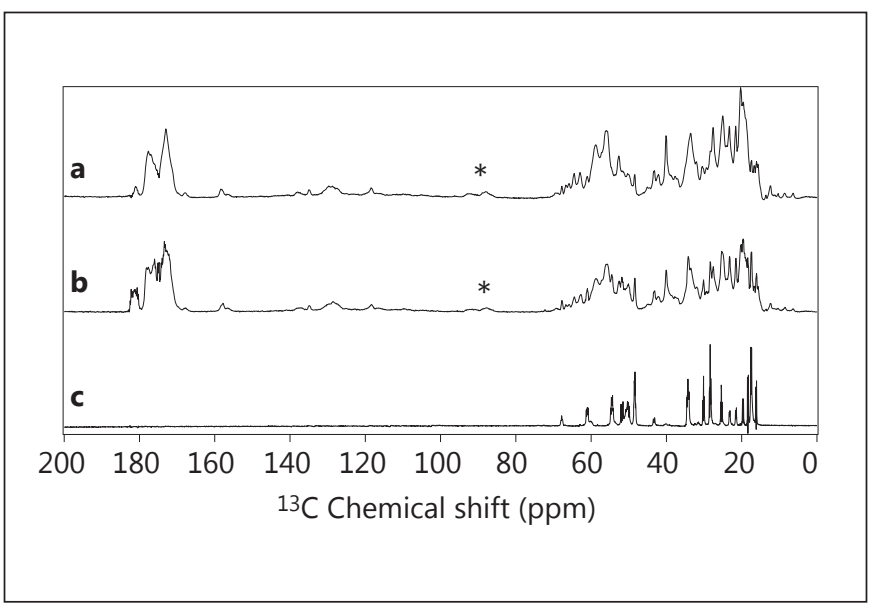

Fig. 4. MAS NMR spectra of gas vesicles of $H$. salinarum at approximately $3^{\circ} \mathrm{C}$ using cross-polarization (a), direct polarization (b), and ${ }^{1} \mathrm{H}_{-}{ }^{13} \mathrm{C}$ INEPT (c). The asterisks identify spinning sidebands.

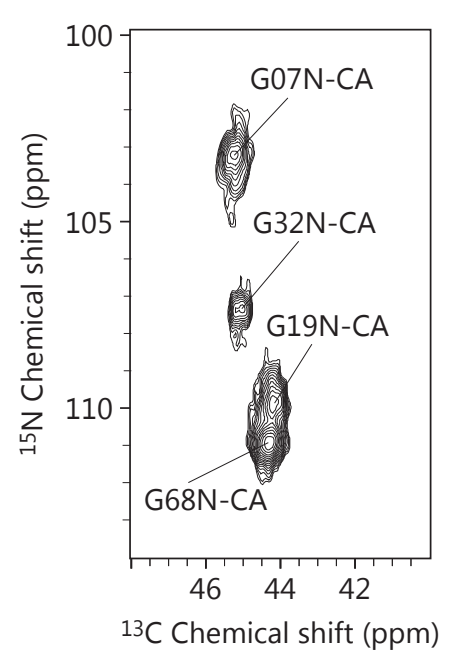

Fig. 5. N-CA correlations in the glycine region observed at 900 $\mathrm{MHz}{ }^{1} \mathrm{H}$ Larmor frequency and $3^{\circ} \mathrm{C}$, using $1.4 \mathrm{~ms}$ of ZF-TEDOR (Z-Filter Transferred Echo Double Resonance) mixing. Signals were assigned as described in the text.
Fig. 6. $\mathrm{CA}-\mathrm{CB}$ correlations in the alanine region observed at $750 \mathrm{MHz}{ }^{1} \mathrm{H}$ Larmor frequency and $3^{\circ} \mathrm{C}$, using $2 \mathrm{~ms}$ of RFDR (Radio Frequency-driven Dipolar Recoupling) mixing (left) or $10 \mathrm{~ms}$ of DARR (Dipolar Assisted Rotational Resonance) mixing (right). Although the two methods differ in polarization transfer characteristics and not all of the peaks have been assigned (see text), the two spectra taken together do not make a case for more than 14 distinct alanine signals.



magnetization along the side chains to carbons with characteristic chemical shifts. This is illustrated in figure 7 by the correlation of ${ }^{13} \mathrm{C}$ signals from the V47 methyl groups with the ${ }^{15} \mathrm{~N}$ and ${ }^{13} \mathrm{C}$ signals from the rest of $\mathrm{V} 47$, and in figure $8 \mathrm{c}$ by the correlation of ${ }^{13} \mathrm{C}$ signals from the $\mathrm{F} 50$ aromatic ring with the ${ }^{15} \mathrm{~N}$ and ${ }^{13} \mathrm{C}$ signals from the rest of F50.

In total, the backbone atoms (and some, if not all, of the side-chain atoms) have been assigned for 52 of the 75 res- idues in GvpA. While most of the highly conserved region (fig. 2) has been assigned, the sole tryptophan and a few other residues in the $\beta$-sheet core are regrettably elusive.

\section{Secondary Structure}

Due to their sensitivity to local electronic structure, chemical shifts reflect local conformation. Figure $9 \mathrm{com}-$ pares the results of two secondary structure analyses of the chemical shifts of GvpA in $H$. salinarum with the 


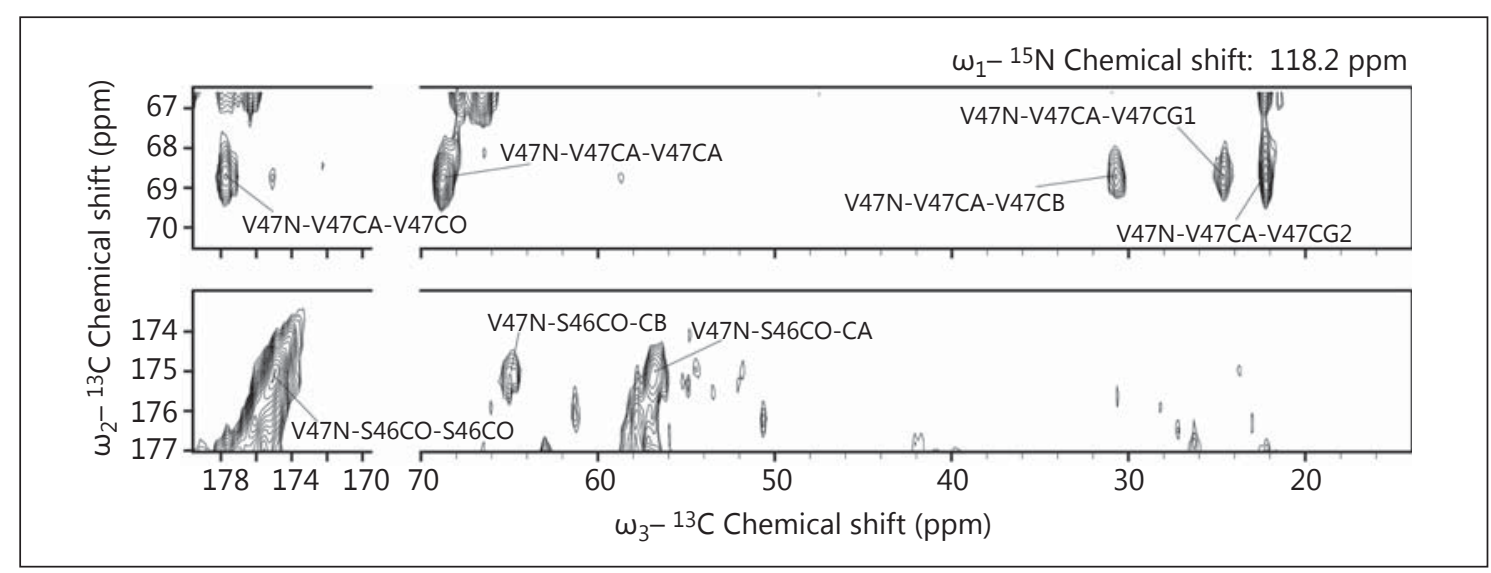

Fig. 7. Slices of the ZF-TEDOR-DARR ${ }^{15} \mathrm{~N}-{ }^{13} \mathrm{C}-{ }^{13} \mathrm{C}$ spectrum at $750 \mathrm{MHz}{ }^{1} \mathrm{H}$ Larmor frequency and $3{ }^{\circ} \mathrm{C}$ showing $\mathrm{NCaCx}$ correlations (top) and NCOCx correlations (bottom) at the ${ }^{15} \mathrm{~N}$ frequency of the V47 amides.

PSIPRED predictions based on the primary sequence. The CA-CB analysis [Luca et al., 2001] compares the observed $\mathrm{CA}$ and $\mathrm{CB}$ chemical shifts for a given residue with the average $\mathrm{CA}$ and $\mathrm{CB}$ chemical shifts for random coil in existing databases (http://spin.niddk.nih.gov/bax/ nmrserver/Poulsen_rc_CS/). TALOS+ [Shen et al., 2009] elaborates by (i) adding consideration of the $\mathrm{N}$ and $\mathrm{CO}$ chemical shifts, (ii) also taking into account the shifts of flanking neighbors, and (iii) supplementing database mining with neural network processing.

As found earlier for A. flos-aquae, the inferences from the experimental data generally agree well with the PSIPRED prediction of an overall coil (c1) - helix ( $\alpha 1)$ strand $(\beta 1)$ - strand $(\beta 2)$ - helix ( $\alpha 2)$ - coil (c2) conformation. Perhaps the most significant discrepancy is that TALOS+ finds the location of the turn between $\beta 1$ and $\beta 2$ shifted slightly toward the $\mathrm{C}$-terminus in $H$. salinarum versus slightly toward the $\mathrm{N}$-terminus in A. flos-aquae. However, the PSIPRED confidence is low in that neighborhood and TALOS is known to have difficulty with regions of irregular structure, including loops and turns [Shen et al., 2009].

\section{Discussion}

In order to confer buoyancy, gas vesicles need to avoid both collapse and condensation of internal water vapor.

\section{Avoiding Water Condensation}

Condensation may occur via either homogeneous or heterogeneous nucleation. The former is very slow: for supersaturation levels of 2-4 (as would occur upon cooling by $10-20^{\circ} \mathrm{C}$ around $300 \mathrm{~K}$ ), rates of homogeneous water nucleation have been estimated at $\sim 1$ event per $\mathrm{cm}^{3}$ per s [Wolk et al., 2002]. Thus, for a typical vesicle with a volume of less than $10^{-14} \mathrm{~cm}^{3}$, it would take more than $10^{14} \mathrm{~s}$, or about a million years, for homogeneous nucleation to occur. Even for supersaturation levels of 6 (as would occur upon cooling by $\sim 30^{\circ} \mathrm{C}$ around $300 \mathrm{~K}$ ), rates of homogeneous water nucleation rise only to $\sim 10^{5}$ events per $\mathrm{cm}^{3}$ per s [Wolk et al., 2002], such that nucleation in a volume of less than $10^{-14} \mathrm{~cm}^{3}$ would take more than $10^{9} \mathrm{~s}$, still on the order of decades. Thus, all that is required to avoid homogeneous nucleation over relevant time periods is to keep the vesicles small.

Heterogeneous nucleation depends on adsorption at the vesicle surface. For a polar molecule like water, a nonpolar surface is less attractive than a polar one. However, even nonpolar surfaces, such as carbon nanotubes, can be hospitable to water via dispersive interactions [Hummer et al., 2001; Kyakuno et al., 2011; Maniwa et al., 2002]. These attractions are minimized by an electron-poor, i.e. proton-rich, composition, as has been observed by X-ray diffraction at the inner surface of gas vesicles [Blaurock and Walsby, 1976]. In this regard, a notable feature of the highly conserved $\beta$-strand sequences of GvpA is the presence of an aliphatic residue at every other site. As a result, the $\beta$-sheet can present a purely aliphatic face if the $\beta$-turn is an odd-membered one. The significance of this constraint will be discussed below.

\section{Avoiding Collapse}

As remarked above, it is experimentally observed, as well as commonsensical, that the critical collapse pres- 


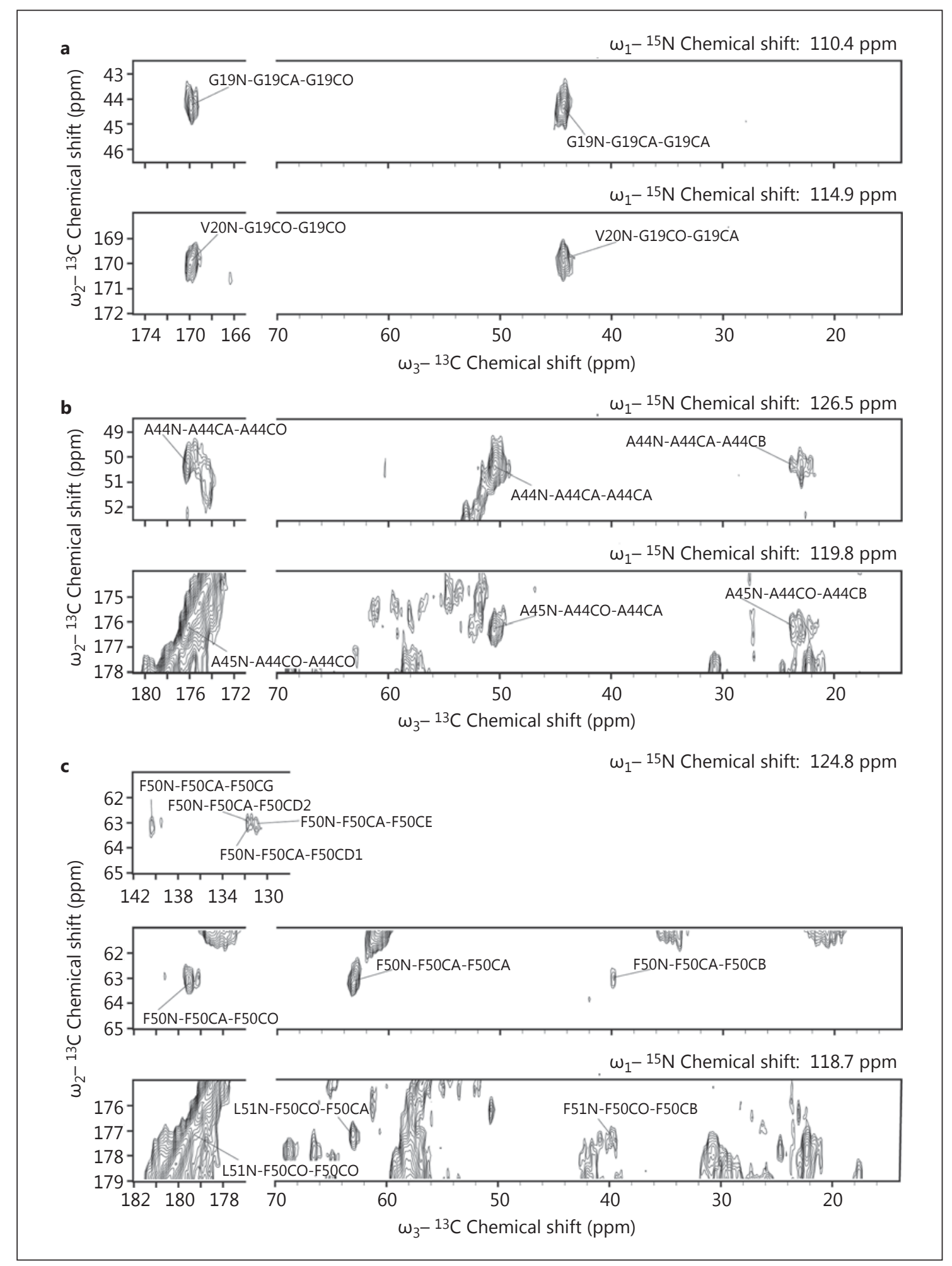

Fig. 8. Slices of the ZF-TEDOR-DARR ${ }^{15} \mathrm{~N}-{ }^{13} \mathrm{C}-{ }^{13} \mathrm{C}$ spectrum at $750 \mathrm{MHz}{ }^{1} \mathrm{H}$ Larmor frequency and $3{ }^{\circ} \mathrm{C}$ showing: a NCACX correlations (top) and NCOCX correlations (bottom) at the ${ }^{15} \mathrm{~N}$ frequencies of the G19 amide (top) and of the V20 amide (bottom); b NCACX correlations (top) and NCOCX correlations (bottom) at the ${ }^{15} \mathrm{~N}$ frequencies of the A44 amide (top) and of the A45 amide (bottom); and c NCACX correlations (top) and NCOCX correlations (bottom) at the ${ }^{15} \mathrm{~N}$ frequencies of the F50 amide (top) and of the L51 amide (bottom). 


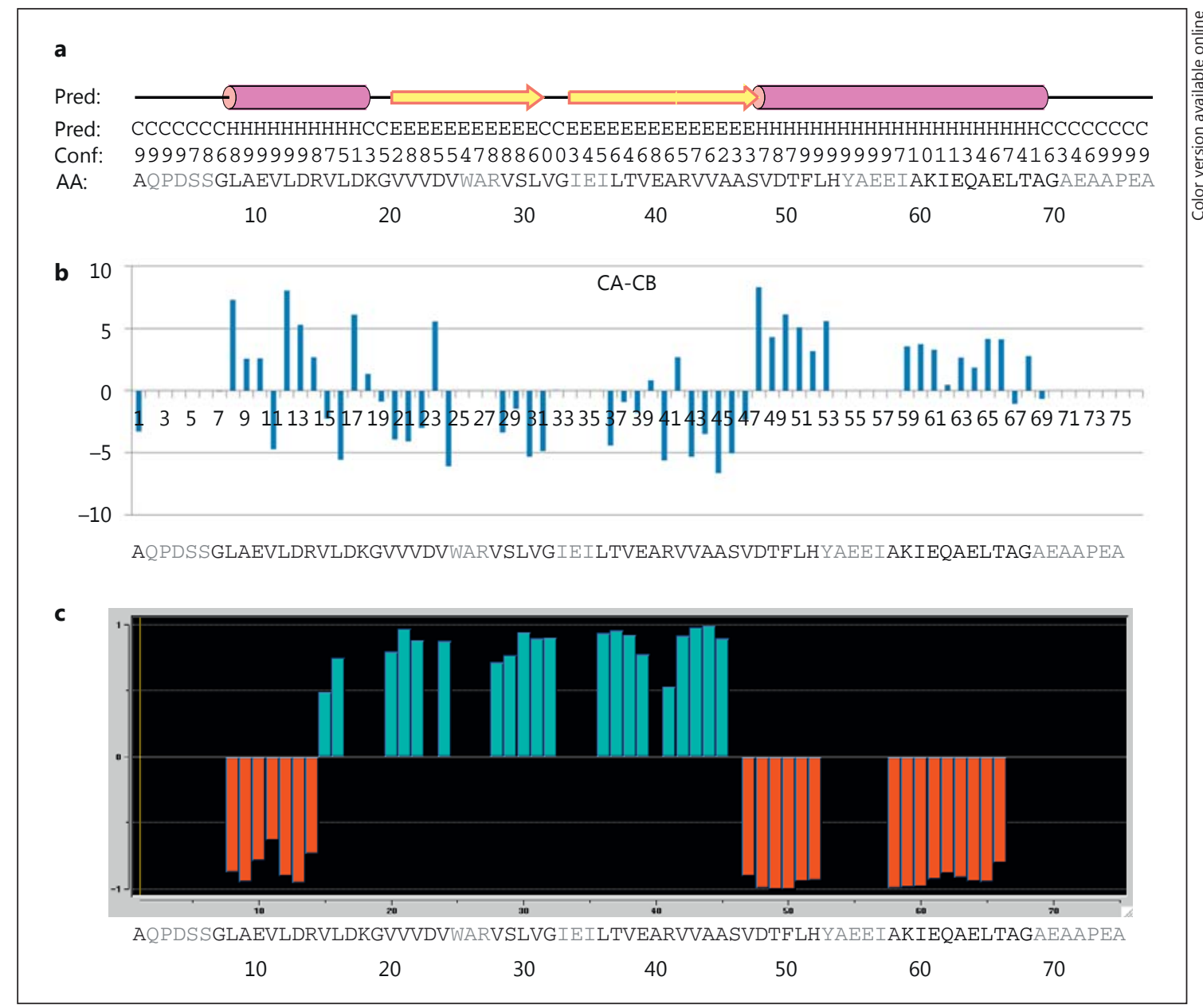

Fig. 9. Secondary structure results for GvpA in H. salinarum. In all panels, the amino acid residues that remain unassigned are shaded in gray. a Repeat of the PSIPRED prediction shown in figure 3. $\mathbf{b}$ Results of CA-CB analysis. Positive and negative values identify helix and strand conformations, respectively. c Results of TALOS+ analysis. Negative and positive values identify helix and strand conformations, respectively.

sures of narrow vesicles are greater than those of wide vesicles. At the same time, more subtle contributions to vesicle strength arise from the numerous hydrogen bonds in the $\beta$-sheet. One important feature appears to be antiparallel strand alignment (between, as well as within, monomers) which allows for more regular, and presumably stronger, hydrogen bonds. In addition, hydrogen bonds oriented at the 'magic angle' of $54^{\circ}$ to the vesicle axis optimally distribute stress [Walsby, 1994]. However, this combination is not easily achieved.

In addition to alternating aliphatic residues, another conspicuous feature of the highly conserved sequences of GvpA is the situation of complementary acidic and basic residues in the nonaliphatic face of $\beta 1$ at D23-R27 and $\beta 2$ at E39-R41. These serve to stabilize an antiparallel dimer arrangement, with noninterchangeable pairs of salt bridges in the $\beta 1-\beta 1$ and $\beta 2-\beta 2$ interfaces, such that the bulky helix and coil segments are distributed on both edges of the $\beta$-sheet (fig. 10). However, as has previously been noted [Sivertsen et al., 2009], if the dimer is symmetric with the $\beta$-turn in both monomers identically centered on the glycine, the hydrogen bonds will be oriented at $70^{\circ}$ from the vesicle axis (fig. 10a). Alternatively (not shown), if the $\beta$-turn in both monomers is identically centered on the neighboring valine (isoleucine), the hydrogen bonds will be oriented at $70^{\circ}\left(42^{\circ}\right)$ from the vesicle axis. On the other hand, the 'magic angle' is achieved if the $\beta$-turn of one monomer is at glycine while the other is at valine (fig. 10b). 


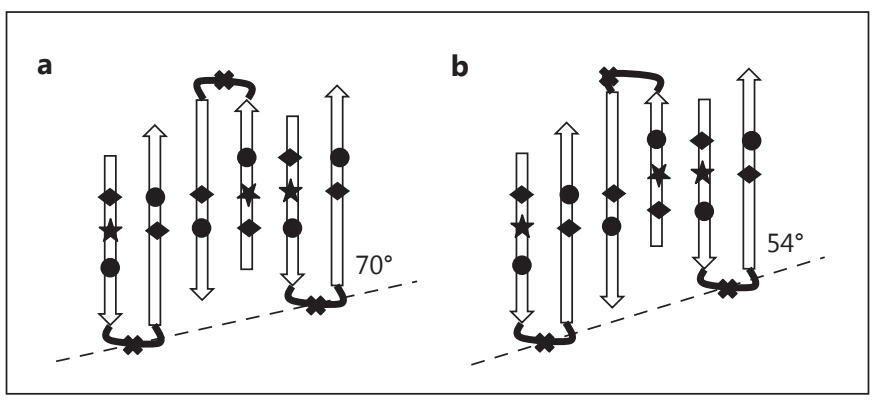

Fig. 10. Schematic representation of two ways of forming an extended, antiparallel $\beta$-sheet along the vesicle rib (dashed lines), employing antiparallel dimers that distribute the helix and coil segments of GvpA on both edges of the sheet. All $\beta$-turns are odd membered so that all the nonaliphatic residues, including the unique tryptophan $(\star)$, are on the side of the sheet facing the reader and all charged residues [carboxylic acids $(\bullet)$ and arginines $(\bullet)]$ are paired in salt bridges. a With a symmetric dimer unit cell in which both $\beta$-turns are centered on glycine $(\mathbf{X})$, the inclinations of the strands to the rib and the hydrogen bonds to the vesicle axis are $70^{\circ} . \mathbf{b}$ With an asymmetric dimer unit cell, in which $\beta$-turns in alternating molecules are centered on valine instead of glycine, the inclinations of the strands to the rib and the hydrogen bonds to the vesicle axis are $54^{\circ}$. Note that the angles do not appear to be of the labeled magnitude because the distances between strands have been rendered on a larger scale than the distances along strands in order to enhance clarity.

This dimorphism is consistent with the NMR data for A. flos-aquae, both with respect to the duplication of signals [Sivertsen et al., 2009] and with respect to distances between residues in the $\beta 1-\beta 1$ and $\beta 2-\beta 2$ interfaces [Bayro et al., 2012]. However, the advantage of the 'magic angle' appears to have been foregone in H. salinarum, since the NMR shows no evidence of dimorphism.

\section{Trade-Offs}

The picture that emerges is that, while $H$. salinarum and $A$. flos-aquae appear to adopt similar strategies with regard to preventing condensation of water vapor inside their gas vesicles, $H$. salinarum, inhabiting shallow brine pools, appears to be able to economize on vesicle strength in ways that $A$. flos-aquae, inhabiting deep fresh water lakes, does not. The evidence available suggests that both species form $\beta$-sheets with one purely aliphatic face. If this face presents to the vesicle interior, it will minimize heterogeneous nucleation of water. The two species also keep their internal volumes small, which has the effect of minimizing homogeneous nucleation of water. However, the rounder $H$. salinarum vesicles achieve volumes comparable to those of the longer and narrower A. flos-aquae vesicles with a smaller surface area and a correspondingly smaller investment in the protein shell. $H$. salinarum also appears to economize by making use of a single, presumably lowest energy, monomer conformation and making do with the resulting suboptimal orientation of the hydrogen bonds. It seems likely that these differences have more to do with adaptation to habitat than with the evolutionary divergence between Bacteria and Archaea. It would be interesting to carry out studies of wide bacterial gas vesicles and narrow archaeal gas vesicles.

\section{Experimental Procedures}

H. salinarum gas vesicles were prepared as described previously [Belenky et al., 2004] except that the $H$. salinarum cells were grown on a uniformly ${ }^{13} \mathrm{C},{ }^{15} \mathrm{~N}$-labeled medium. The isolated ${ }^{13} \mathrm{C},{ }^{15} \mathrm{~N}$-labeled gas vesicles were collapsed by a pressure pulse, washed and then centrifuged into Bruker $3.2 \mathrm{~mm}$ zirconia rotors following the protocol applied previously to A. flos-aquae vesicles [Sivertsen et al., 2009].

One-dimensional ${ }^{13} \mathrm{C}$ spectra (fig. 4) were acquired at $750 \mathrm{MHz}$ ${ }^{1} \mathrm{H}$ Larmor frequency and $16 \mathrm{kHz}$ MAS. The cross-polarization [Metz et al., 1994; Pines et al., 1972] and direct-polarization spectra are the averages of 512 scans each, whereas the spectrum from INEPT [Morris and Freeman, 1979] is the average of 1,600 scans.

The $2 \mathrm{D}{ }^{15} \mathrm{~N}-{ }^{13} \mathrm{C}$ ZF-TEDOR [Jaroniec et al., 2002] spectrum (fig. 5) was obtained at $900 \mathrm{MHz}{ }^{1} \mathrm{H}$ Larmor frequency and 16.6 $\mathrm{kHz}$ MAS, using a triple-resonance $3.2 \mathrm{~mm}{ }^{1} \mathrm{H} /{ }^{13} \mathrm{C} /{ }^{15} \mathrm{~N}$ E-free probe (Bruker Biospin, Billerica, Mass., USA). The mixing period was optimized for one-bond transfers at $1.4 \mathrm{~ms}$ and $83 \mathrm{kHz}$ twopulse phase modulation (TPPM) decoupling [Bennett et al., 1995] was applied during the evolution and detection periods. The spectrum was recorded with 250 real and 250 imaginary points in the indirect dimension and 4,096 points in the direct dimension, with dwell times of 60 and $6 \mu$ s, respectively. The spectra are the average of 128 transients per $\mathrm{t} 1$ point.

Two-dimensional ${ }^{13} \mathrm{C}-{ }^{13} \mathrm{C}$ spectra (fig. 6) were acquired at 750 $\mathrm{MHz}{ }^{1} \mathrm{H}$ Larmor frequency and $16 \mathrm{kHz}$ MAS. The RFDR [Bayro et al., 2008; Bennett et al., 1992, 1998] mixing time was optimized for one-bond transfers at $2 \mathrm{~ms}$. The DARR [Takegoshi et al., 2001; Veshtort and Griffin, 2011] mixing time was optimized for one- to two-bond transfers at $10 \mathrm{~ms}$. Both experiments made use of $83 \mathrm{kHz}$ TPPM decoupling [Bennett et al., 1995] during the evolution and detection periods. Both experiments were recorded with 500 real and 500 imaginary points in the indirect dimension and 1,536 points in the direct dimension, with dwell times of 20 and $14 \mathrm{~ms}$, respectively. The spectra are the average of 48 transients per 11 point.

The $3 \mathrm{D}{ }^{15} \mathrm{~N}-{ }^{13} \mathrm{C}-{ }^{13} \mathrm{C}$ spectra (fig. 7) were acquired at $750 \mathrm{MHz}$ ${ }^{1} \mathrm{H}$ Larmor frequency and $16 \mathrm{kHz}$ MAS using a triple-resonance $3.2 \mathrm{~mm}{ }^{1} \mathrm{H} /{ }^{13} \mathrm{C} /{ }^{15} \mathrm{~N}$ E-free probe (Bruker Biospin). The $90^{\circ}{ }^{15} \mathrm{~N}$ and ${ }^{13} \mathrm{C}$ pulses were 5 and $2.5 \mu$ s, respectively. TPPM decoupling was $83 \mathrm{kHz}$ during the gaps between the $180^{\circ}$ pulses and acquisition, and $100 \mathrm{kHz}$ during evolution. Mixing periods were $1.5 \mathrm{~ms}$ for ZF-TEDOR and $40 \mathrm{~ms}$ for DARR, the latter chosen to transfer polarization into the protein side-chains. The $3 \mathrm{D}$ data set was ac- 
quired using $60 \times 220 \times 896$ points, with dwell times of 125,34 and $20 \mu \mathrm{s}$, for $\omega_{1}, \omega_{2}$ and $\omega_{3}$, respectively. Each FID averaged four scans, using a recycle delay of $2.6 \mathrm{~s}$, for a total experimental time of 6.3 days.

All spectra were referenced to external 2,2-dimethyl-2-silapentane-5-sulfonic acid [Morcombe and Zilm, 2003]. All data sets were processed with the NMRPipe package [Delaglio et al., 1995] and analyzed using Sparky (T.D. Goddard and D.G. Kneller, SPARKY 3, University of California, San Francisco, Calif., USA).

\section{Acknowledgements}

Research reported in this publication was supported by the $\mathrm{Na}$ tional Institute of Biomedical Imaging and Bioengineering of the National Institutes of Health under awards EB001035, EB001960 and EB002026. The content is solely the responsibility of the authors and does not necessarily represent the official views of the National Institutes of Health.

\section{References}

- Bayro MJ, Daviso E, Belenky M, Griffin RG, Herzfeld J: An amyloid organelle, solid-state NMR evidence for cross- $\beta$ assembly of gas vesicles. J Biol Chem 2012;287:3479-3484.

-Bayro MJ, Ramachandran R, Caporini MA, Eddy MT, Griffin RG: Radio frequency-driven recoupling at high magic-angle spinning frequencies: homonuclear recoupling sans heteronuclear decoupling. J Chem Phys 2008, 128:052321.

Belenky M, Meyers R, Herzfeld J: Subunit structure of gas vesicles: a MALDI-TOF mass spectrometry study. Biophys J 2004;86:499-505.

Bennett AE, Ok JH, Griffin RG, Vega S: Chemical shift correlation spectroscopy in rotating solids: radio frequency-driven dipolar recoupling and longitudinal exchange. J Chem Phys 1992;96:8624-8627.

Bennett AE, Rienstra CM, Auger M, Lakshmi KV, Griffin RG: Heteronuclear decoupling in rotating solids. J Chem Phys 1995;103:69516958.

- Bennett AE, Rienstra CM, Griffiths JM, Zhen WG, Lansbury PT, Griffin RG: Homonuclear radio frequency-driven recoupling in rotating solids. J Chem Phys 1998;108:9463-9479.

Blaurock AE, Walsby AE: Crystalline structure of gas vesicle wall from Anabaena flos-aquae. J Mol Biol 1976;105:183-199.

Blaurock AE, Wober W: Structure of the wall of Halobacterium halobium gas vesicles. J Mol Biol 1976;106:871-888.

Daviso E, Eddy MT, Andreas LB, Griffin RG, Herzfeld J: Efficient resonance assignment of proteins in MAS NMR by simultaneous intraand inter-residue 3D correlation spectroscopy. J Biomol NMR 2013:55;257-265.

Delaglio F, Grzesiek S, Vuister GW, Zhu G, Pfeifer J, Bax A: NMRPipe: a multidimensional spectral processing system based on UNIX pipes. J Biomol NMR 1995;6:277-293.

Ezzeldin HM, Klauda JB, Solares SD: Modeling of the major gas vesicle protein, GvpA: from protein sequence to vesicle wall structure. J Struct Biol 2012;179:18-28.

-Hummer G, Rasaiah JC, Noworyta JP: Water conduction through the hydrophobic channel of a carbon nanotube. Nature 2001;414:188190. aroniec CP, Filip C, Griffin RG: 3D TEDOR NMR experiments for the simultaneous measurement of multiple carbon-nitrogen distances in uniformly ${ }^{13} \mathrm{C},{ }^{15} \mathrm{~N}$-labeled solids. J Am Chem Soc 2002;124:10728-10742.

Kyakuno H, Matsuda K, Yahiro H, Inami Y, Fukuoka T, Miyata Y, Yanagi K, Maniwa Y, Kataura H, Saito T, Yumura M, Iijima S: Confined water inside single-walled carbon nanotubes: global phase diagram and effect of finite length. J Chem Phys 2011;134: 244501.

Luca S, Filippov DV, van Boom JH, Oschkinat H, de Groot HJM, Baldus M: Secondary chemical shifts in immobilized peptides and proteins: a qualitative basis for structure refinement under magic angle spinning. J Biomol NMR 2001;20:325-331.

Maniwa Y, Kataura H, Abe M, Suzuki S, Achiba Y, Kira H, Matsuda K: Phase transition in confined water inside carbon nanotubes. J Phys Soc Jap 2002;71:2863-2866.

McMaster TJ, Miles MJ, Walsby AE: Direct observation of protein secondary structure in gas vesicles by atomic force microscopy. Biophys J 1996;70:2432-2436.

Metz G, Wu XL, Smith SO: Ramped amplitude cross-polarization in magic-angle-spinning NMR. J Magn Reson Ser A 1994;110:219-227.

Morcombe CR, Zilm KW: Chemical shift referencing in MAS solid state NMR. J Magn Reson 2003;162:479-486.

Morris GA, Freeman R: Enhancement of nuclear magnetic-resonance signals by polarization transfer. J Am Chem Soc 1979;101:760-762.

-Offner S, Ziese U, Wanner G, Typke D, Pfeifer F: Structural characteristics of halobacterial gas vesicles. Microbiology 1998;144:1331-1342.

Omelchenko MV, Vasilyeva LV, Zavarzin GA: Psychrophilic methanotroph from tundra soil. Curr Microbiol 1993;27:255-259.

Pines A, Waugh JS, Gibby MG: Proton-enhanced nuclear induction spectroscopy: method for high resolution NMR of dilute spins in solids. J Chem Phys 1972;56:1776-1777.

Ramsay JP, Williamson NR, Spring DR, Salmond GPC: A quorum-sensing molecule acts as a morphogen controlling gas vesicle organelle biogenesis and adaptive flotation in an enterobacterium. Proc Natl Acad Sci USA 2011; 108:14932-14937.
Shen Y, Delaglio F, Cornilescu G, Bax A: TALOS+: a hybrid method for predicting protein backbone torsion angles from NMR chemical shifts. J Biomol NMR 2009;44:213-223.

-Sivertsen AC, Bayro MJ, Belenky M, Griffin RG, Herzfeld J: Solid-state NMR evidence for inequivalent GvpA subunits in gas vesicles. J Mol Biol 2009;387:1032-1039.

Sivertsen AC, Bayro MJ, Belenky M, Griffin RG, Herzfeld J: Solid-state NMR characterization of gas vesicle structure. Biophys J 2010;99: 1932-1939.

Strunk T, Hamacher K, Hoffgaard F, Engelhardt H, Zillig MD, Faist K, Wenzel W, Pfeifer F: Structural model of the gas vesicle protein GvpA and analysis of GvpA mutants in vivo. Mol Microbiol 2011;81:56-68.

Takegoshi K, Nakamura S, Terao T: ${ }^{13} \mathrm{C}-{ }^{1} \mathrm{H}$ dipolar-assisted rotational resonance in magic-angle spinning NMR. Chem Phys Lett 2001;344: 631-637.

Veshtort M, Griffin RG: Proton-driven spin diffusion in rotating solids via reversible and irreversible quantum dynamics. J Chem Phys 2011;135:134509.

-Walker JE, Hayes PK, Walsby AE: Homology of gas vesicle proteins in cyanobacteria and halobacteria. J Gen Microbiol 1984;130: 2709-2715.

Walsby AE: Permeability of blue-green algal gasvacuole membranes to gas. Proc R Soc Lond Ser B 1969;173:235-255.

Walsby AE: Permeability of gas vesicles to perfluorocyclobutane. J Gen Microbiol 1982;128: 1679-1684.

Walsby AE: Gas vesicles. Microbiol Rev 1994;58: 94-144.

Walsby AE, Hayes PK: The minor cyanobacterial gas vesicle protein, $\mathrm{GvpC}$, is attached to the outer surface of the gas vesicle. J Gen Microbiol 1988; 134:2647-2657.

Walsby AE, Revsbech NP, Griffel DH: The gaspermeability coefficient of the cyanobacterial gas vesicle wall. J Gen Microbiol 1992;138: 837-845

Walsby AE, Simpson JH: Lower limit of the gaspermeability coefficient of gas vesicles. Proc $\mathrm{R}$ Soc Lond Ser B 1984;223:177-196.

Wolk J, Strey R, Heath CH, Wyslouzil BE: Empirical function for homogeneous water nucleation rates. J Chem Phys 2002;117:4954-4960.
Gas Vesicles across Kingdoms:

A Comparative Solid-State NMR Study
J Mol Microbiol Biotechnol 2013;23:281-289 DOI: $10.1159 / 000351340$ 